Research Paper

\title{
PPAR $\delta$ inhibition protects against palmitic acid-LPS induced lipidosis and injury in cultured hepatocyte L02 cell
}

\author{
Yi Li ${ }^{*}$, Chenwei Wang ${ }^{*}$, Jiyuan Lu ${ }^{1}$, Ke Huang${ }^{1}$, Yu Han² ${ }^{2}$ Junlin Chen ${ }^{1}$, Yan Yang ${ }^{3 凶}$, Bin Liu ${ }^{1 凶}$ \\ 1. School/Hospital of Stomatology, Lanzhou University, Lanzhou, China \\ 2. College of Life Science \& Technology, Huazhong University of Science and Technology, Wuhan, China \\ 3. Department of Endocrinology, Gansu Provincial Hospital, Lanzhou, China \\ *These authors contributed equally to the work. \\ $\bowtie$ Corresponding authors: yanzi2004099@sina.com (Y.Y.); liubkq@lzu.edu.cn (B.L.) \\ (c) The author(s). This is an open access article distributed under the terms of the Creative Commons Attribution License (https://creativecommons.org/licenses/by/4.0/). \\ See http://ivyspring.com/terms for full terms and conditions.
}

Received: 2019.06.17; Accepted: 2019.08.22; Published: 2019.10.21

\begin{abstract}
Background: Non-alcoholic fatty liver disease (NAFLD) is the most common chronic liver disease, and its pathogenesis and mechanism are intricate. In the present study, we aimed to evaluate the role of PPAR $\delta$ in LPS associated NAFLD and to investigate the signal transduction pathways underlying PPAR $\delta$ treatment in vitro. Material and Methods: L02 cells were exposed to palmitic acid (PA) and/or LPS in the absence or presence of PPAR $\delta$ inhibition and/or activation. Results: LPS treatment markedly increased lipid deposition, FFA contents, IL-6 and TNF- $\alpha$ levels, and cell apoptosis in PA treatment (NAFLD model). PPAR $\delta$ inhibition protects $L 02$ cells against LPS-induced lipidosis and injury. Conversely, the result of PPAR $\delta$ activation showed the reverse trend. LPS+PA treatment group significantly decreases the relative expression level of IRS-1, PI3K, AKT, phosphorylation of AKT, TLR-4, MyD88, phosphorylation of IKKa, NF-KB, Bcl-2 and increases the relative expression level of Bax, cleaved caspase 3 and cleaved caspase 8, compared with the cells treated with NAFLD model. PPAR $\delta$ inhibition upregulated the related proteins' expression level in insulin resistance and inflammation pathway and downregulated apoptotic relevant proteins. Instead, PPAR $\delta$ agonist showed the reverse trend. Conclusion: Our data show that PPAR $\delta$ inhibition reduces steatosis, inflammation and apoptosis in LPS-related NAFLD damage, in vitro. PPAR $\delta$ may be a potential therapeutic implication for NAFLD.
\end{abstract}

Key words: Non-alcoholic fatty liver disease; PPAR 8; L02 Cell

\section{Introduction}

Non-alcoholic fatty liver disease (NAFLD) is the most common chronic liver disease in many countries [1]. NAFLD is characterized by a wide spectrum of manifestations ranging from simple steatosis, non-alcoholic steatohepatitis (NASH) to advanced fibrosis and may evolve to liver cirrhosis and hepatocellular carcinoma (HCC) [2-5]. NAFLD is becoming the most common liver disease affecting liver transplantation [6]. Although many different pharmacotherapeutic strategies have been used in clinic, such as thiazolidinediones, vitamin E, losartan and silybin taking orally, the impact of these therapies is still not satisfactory [7-10]. Therefore, further study on the pathogenesis and mechanism of NAFLD will be beneficial in the treatment of NAFLD.

It is generally recognized that the causes of NAFLD are associated with heredity, diet, insulin resistance (IR) and adipokine, as well as potential factors which need to be further verified, including endocrine disruptors (such as bisphenol A, phthalates) and ecological disorders of intestinal flora [11-16]. Recent studies suggest that the gut microbiota contributes to metabolic liver disease [17-19]. It has been well established that gut microbiota controls the 
gut barrier function and, therefore, the progression of 'metabolic endotoxaemia' characterised by the translocation of specific microbe-associated molecular patterns such as lipopolysaccharides (LPS) into the systemic circulation [20-23]. Gut-derived bacterial LPS is brought to the liver by the portal circulation, which combines with Toll-like receptor 4 (TLR-4) complexes on liver cell surface and induces the production of inflammatory cytokines [24-26]. LPS might result in low-grade chronic inflammation and thereby cause insulin resistance, contributing to the development of NAFLD [27-30]. However, the role of LPS in development of NAFLD has not been fully elucidated.

Peroxisome proliferator-activated receptor $\delta$ (PPAR $\delta$ ) is a metabolic regulator, with biological functions in skeletal muscle, fat, intestine, liver and the heart [31]. Evidences suggest that PPAR $\delta$ activation enhances free fatty acids (FFAs) transport and oxidation, improves glucose homeostasis through improvement of insulin sensitivity and inhibition of glucose output, attenuates macrophage inflammatory responses, and increases plasma high-density lipoprotein (HDL) concentrations [32-35]. In the mouse model of NASH, PPAR $\delta$ improves hepatic steatosis and inflammation by regulation of lipid metabolism and inhibition of inflammatory response [36]. By contrast, little is known about the role of PPAR $\delta$ during NAFLD with a high LPS level.

Therefore, we hypothesized that LPS play a role in development of NAFLD and that PPAR $\delta$ may be a key factor during the process. The aim of this study is to explore the effect of LPS in NAFLD and investigate whether PPAR $\delta$ could exert influence in the lipid deposition and inflammatory response relating to LPS in vitro.

\section{Materials and Methods}

\section{Cell Culture}

Human hepatocyte L02 cell line was obtained from the Chinese Academy of Sciences Cell Bank (Shanghai, China) and cultured in Roswell Park Memorial Institute (RPMI) 1640 Medium (Gibco, Grand Island, NY, USA) supplemented with 10\% (v/v) fetal bovine serum (Invitrogen, Carlsbad, CA, USA), $100 \mathrm{U} / \mathrm{mL}$ penicillin and $100 \mu \mathrm{g} / \mathrm{mL}$ streptomycin in $5 \% \mathrm{CO} 2$ at $37^{\circ} \mathrm{C}$. The medium was changed every 2-3 days, and the cells were passaged for subculturing or subsequent experiments when they grew to $80 \%$ confluence.

\section{Targeted PPAR $\delta$ inhibition and activation}

For PPAR $\delta$ activation, we use $0.5 \mu \mathrm{mol} / \mathrm{L}$ GW0742 (Selleck Chemicals, Houston, TX, USA), a PPAR $\delta$-selective agonist, for 24h. For PPAR $\delta$ inhibition, the siRNA target sequence used for PPAR $\delta$ knockdown (si-PPAR $\delta$ ). The PPAR $\delta$-specific siRNA gene sequence was 5'-GCAAACCCUUCAG UGAUAUTT $-3^{\prime}$ and the gene sequence of negative control siRNA (N.C. siRNA) was 5'-UUCUCCGAA CGUGUCACGUTT -3 '. PPAR $\delta$ siRNA and N.C. siRNA was purchased from GenePharma (GenePharma, Shanghai, China). L02 cells were used transfected with $20 \mathrm{pmol}$ of N.C. siRNA or PPAR $\delta$-specific siRNA, using Lipofectamine 2000 and Opti-MEM media (Life Technologies, Gaithersburg, MD, USA) after seeding cells attached to the bottom. After 24h PPAR $\delta$ activation or transfection, L02 cells were harvested and immediately subjected to isolation of total RNA and protein. For confirming the PPAR $\delta$ knockdown and over expression efficiency, real-time-PCR and Western blot analyses were performed on the isolated total RNA and protein, respectively. Negative control siRNA (N.C. siRNA) or PPAR $\delta$ siRNA-transfected L02 cells were incubated in $0.4 \mathrm{mM}$ palmitic acid or/and $800 \mathrm{ng} / \mathrm{ml}$ LPS for $24 \mathrm{~h}$. L02 cells were exposed to $0.4 \mathrm{mM}$ palmitic acid (PA) or (and) $800 \mathrm{ng} / \mathrm{ml}$ LPS with or without 1nM GW0742 treatment.

\section{Hoechst 33342 Staining Assay}

Cells grown on a sterile cover slip in twelve-well plates were treated with different concentrations of the test compound for $24 \mathrm{~h}$. The culture medium containing compounds was then removed, and the cells were fixed in $4 \%$ paraformaldehyde for $10 \mathrm{~min}$ at room temperature. After being washed twice with phosphate buffer saline (PBS), the cells were stained with $0.5 \mathrm{~mL}$ of $10 \mu \mathrm{g} / \mathrm{mL}$ Hoechst 33342 (Invitrogen, Eugene, OR, USA) for $10 \mathrm{~min}$ at room temperature. The coverslips were then washed three times with PBS, placed onto glass slides, and covered with mounting medium. The stained nuclei were observed under a fluorescence microscope (Olympus, Tokyo, Japan).

\section{Oil Red O Staining}

Cells cultured on sterile cover slips in twelve-well plates were treated with different concentrations of the test compound for $24 \mathrm{~h}$. The oil red $\mathrm{O}$ staining (Nanjing Jiancheng Bioengineering Institute, Nanjing, China) was conducted based on a standard protocol as follows. Cultured cells were washed three times with PBS and fixed with $4 \%$ formaldehyde for $10 \mathrm{~min}$ at room temperature. Subsequently, cells were stained with oil red $\mathrm{O}$ working solution for $15 \mathrm{~min}$ at room temperature and washed three times with $\mathrm{ddH}_{2} \mathrm{O}$. The nuclear was stained with hematoxylin for another $5 \mathrm{~min}$. The cover slips were then washed three times with $\mathrm{ddH}_{2} \mathrm{O}$, placed onto glass slides, and covered with mounting 
medium. The images were recorded under a light microscope (OLYMPUS) at 400× magnification.

\section{FFA content measurement}

The FFA content measurement kit was obtained from Nanjing Jiancheng Bioengineering Institute (Nanjing, China). Cells were seeded in a density of $10^{6}$ cells/culture-flasks either for control group (containing only medium with supplements) or each treated group for $24 \mathrm{~h}$. Then collected the supernatant for each group after 5, $000 \mathrm{rpm}$ centrifugation. The free fatty acid assay was performed according to the manufacturer's instructions.

\section{Annexin V-FITC/ propidium iodide (PI) double staining}

According to the manufacturer's instructions of annexin-V FITC apoptosis kit (BD, San Jose, CA, USA), cells were cultivated in a density of $10^{6}$ cells/culture-flasks either for control group (containing only medium with supplements) or other treated groups for $24 \mathrm{~h}$. Then, the cells were collected and washed twice with PBS and then resuspended in $100 \mu \mathrm{L} 1 \times$ binding buffer. The cells were subjected to $5 \mu \mathrm{L}$ of FITC Annexin V and $5 \mu \mathrm{L}$ PI staining and incubated for $30 \mathrm{~min}$ at room temperature in the dark. Afterward, $100 \mu \mathrm{L} 1 \times$ binding buffer were added. The apoptosis ratio was quantified by system software (Cell Quest; BD Biosciences, Becton Dickinson FACS AriaIII, NY, USA).

\section{The relative expression level of IL- 6 and TNF- $\alpha$}

The expression level of IL-6 and TNF- $\alpha$ were measured by commercially available enzyme-linked immunosorbent assays kit (Neobioscience technology company, Beijing, China) according to the manufacturer's protocol. All values were expressed as the mean of the three determinations. The concentration was determined by standard curve. All analyses were performed at least three times for each individual cell-stimulation assay.

\section{Western blot analysis}

L02 cells were lysed using Protein Extraction Reagent (Invitrogen, Carlsbad, CA, USA) after treatment. The protein concentration was determined using the bicinchoninic acid (BCA) method. Equal amounts $(40 \mu \mathrm{g})$ of total proteins were boiled for 5 min and subjected to sodium dodecyl sulfate-polyacrylamide gel electrophoresis (SDSPAGE), followed by electrotransfer to polyvinylidene difluoride (PVDF) membranes. The membranes were blocked with nonfat dried milk for $3 \mathrm{~h}$ at room temperature. Then the membranes were then incubated with $\beta$-actin (Abcam, Cambridge, UK),
PPAR $\delta$ (Abcam, Cambridge, UK), insulin receptor substrate-1 [(IRS-1), Abcam, Cambridge, UK], phosphoinositide 3-kinase [(PI3K), Abcam, Cambridge, UK], phospho- protein kinase $\mathrm{B}[(\mathrm{AKT})$, CST, Beverly, MA, USA], p-AKT (CST, Beverly, MA, USA), Toll-like receptor 4 (TLR-4) [Proteintech, Rosemont, PA, USA], myeloid differentiation primary response gene 88 [(MyD88) Proteintech, Rosemont, PA, USA], inhibitor of nuclear factor kappa-B kinase a [(IKKa) CST, Beverly, MA, USA], p-IKKa (CST, Beverly, MA, USA), NF-kB1 (CST, Beverly, MA, USA), Bcl-2 (Proteintech, Rosemont, PA, USA), Bax (Proteintech, Rosemont, PA, USA), caspase-3 (Proteintech, Rosemont, PA, USA) and caspase- 8 (Proteintech, Rosemont, PA, USA) antibodies (1:1,000 dilution) overnight at $4{ }^{\circ} \mathrm{C}$. The levels of $\beta$-actin were used as loading controls. The bands were visualized with an enhanced chemiluminescent direct labeling (ECL) system. The Gel Pro Analyzer 4.5 (Media Cybernetics; Silver Spring, MD, United States) was used to determine the band density. The quantification of band intensity was performed by using Quantity One software (Bio-Rad, CA, USA).

\section{Statistical Analysis}

Statistical analyses of the results from the present study were performed using SPSS18.0. Data are expressed as mean \pm standard deviation (SD). Statistical comparisons of the results were made by using analysis of variance (ANOVA). A level of $p<$ 0.05 was considered statistically significant.

\section{Result}

\section{The effect of PPAR $\delta$ on LPS-mediated lipid deposition progress of NAFLD}

As shown in Figure 1A, $800 \mathrm{ng} / \mathrm{ml}$ LPS treatments visibly raised intracellular lipid accumulation, with more lipid droplets than those of PA group. In addition, the FFA content measurement also suggested that $800 \mathrm{ng} / \mathrm{ml}$ LPS treatments upregulated the content of FFA (Figure 1Ba).

Then, we detected PPAR $\delta$ inhibition and activation on the impact of insulin resistance, since lipid accumulation and FFA expression are known to play critical roles in the insulin resistance. As shown in Figure 1A, si-PPAR $\delta$ treated group visibly had less lipid accumulation in cells. Meanwhile, the FFA content measurement also showed that si-PPAR $\delta$ treatments downregulated the content of FFA (Figure 1Ba). GW0742 sharply increased lipid accumulation (Figure 1C). In consistent with this, the content of FFA had a significant development in the GW0742 treated group (Figure 1Bb). 
A
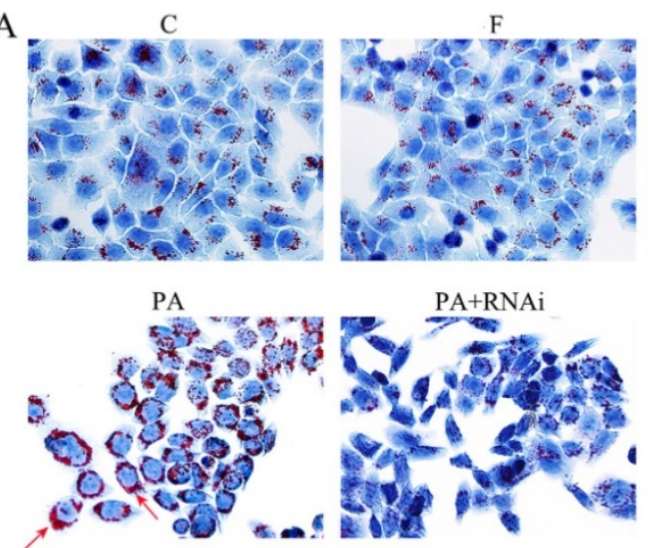

$\mathrm{B}$

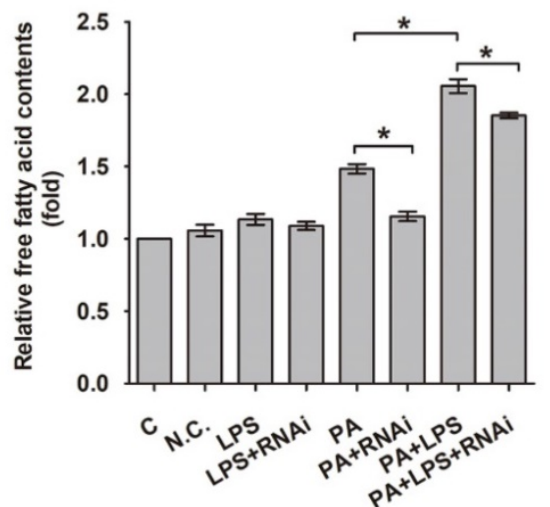

$\mathrm{C}$
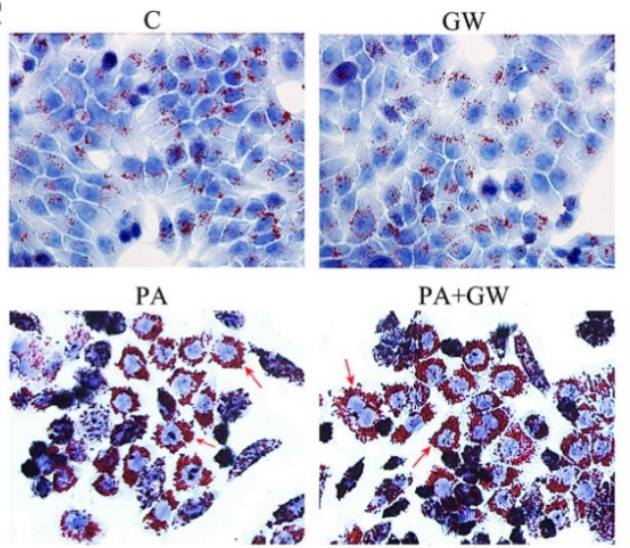
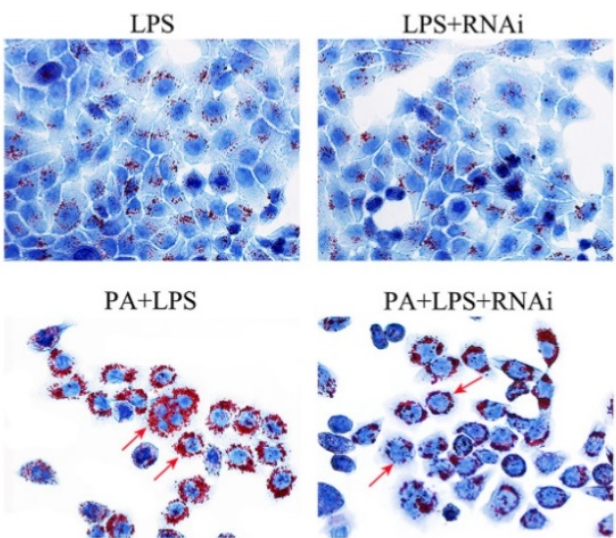

PA+LPS+RNAi

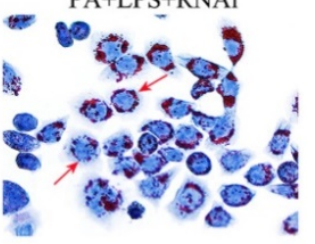

b

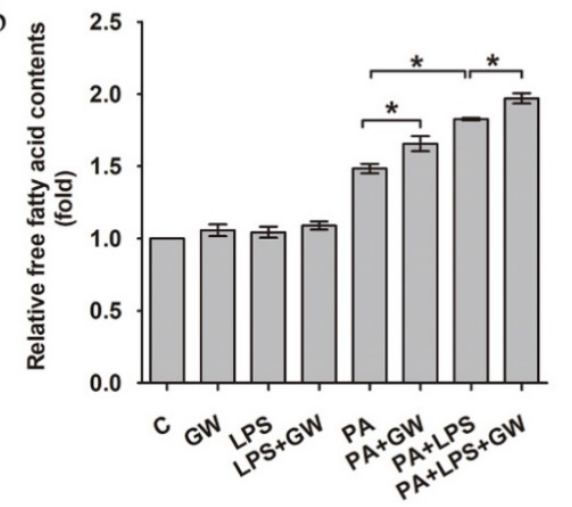

Figure 1. (A) Oil red $O$ staining results of $L 02$ cells were incubated in $0.4 \mathrm{mM}$ palmitic acid or (and) $800 \mathrm{ng} / \mathrm{ml} L P S$ after N.C siRNA or PPAR $\delta$ siRNA interference arrowheads showed obvious red lipid droplets by Oil-red O stain (magnification, $\times 400$ ). (B) The relative free fatty acid contents. (a) L02 cells were treated with N.C. siRNA or PPAR $\delta$ siRNA, (b) L02 cells were treated with or without GW0742 (*P $<0.05)$. (C) Oil red O staining results of L02 cells were incubated in $0.4 \mathrm{mM}$ palmitic acid or (and) $800 \mathrm{ng} / \mathrm{ml} \mathrm{LPS}$ with or without GW0742 conditioning, arrowheads showed obvious red lipid droplets by Oil-red O stain (magnification, ×400). PA, palmitic acid. GW, GW0742.

The protein expression level of IRS-1, PI3K, AKT and p-AKT was significantly lower in PA+LPS group than in the PA group (Figure 2A a-e). Si-PPAR $\delta$ group showed a marked increase in the IRS-1, PI3K, AKT and p-AKT expression (Figure 2A a-e). On the contrary, GW0742 treated groups presented with lower protein expression levels of IRS-1, PI3K and p-AKT in comparison to the agonist untreated PA and PA+LPS group (Figure 2B a, b, c, e), whereas there was no change of AKT expression level between PA group and $\mathrm{PA}+\mathrm{GW}$ group (Figure $2 \mathrm{~B} \mathrm{~d}$ ).

\section{The effect of PPAR $\delta$ on LPS-mediated expression levels of IL-6 and TNF- $\alpha$}

Increased production of cytokines such as IL-6 and TNF- $\mathrm{a}$ is one of the earliest events in many types of liver injury [37]. As can be seen in Figure 3A and B, $800 \mathrm{ng} / \mathrm{ml}$ LPS promotes the expression of IL- 6 and TNF-a significantly, aggravating the level of inflammation. Compared with the PA group and LPS+PA group, si-PPAR $\delta$ downregulated the inflammatory cytokine level of IL-6 and TNF-a (Figure 3A). In contrast, GW0742 upregulated the level of IL-6 and TNF-a (Figure 3B), which suggests PPAR $\delta$ regulates inflammatory reaction. 


\section{A a LPS}

PA

PPAR $\beta / \delta$ RNAi

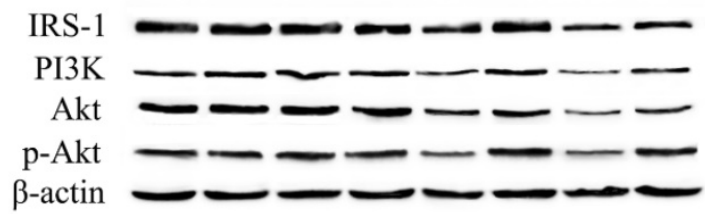

b
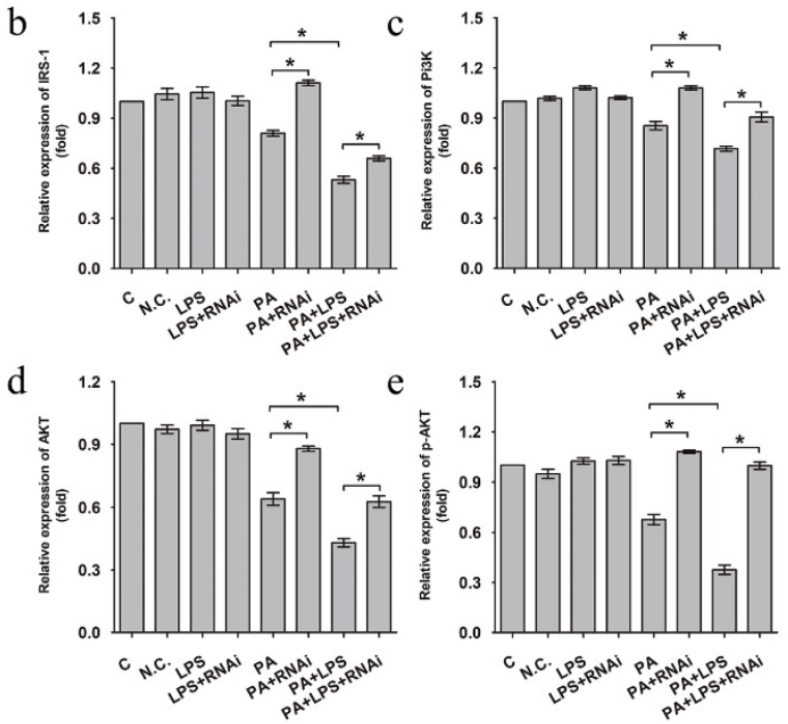

B a LPS

PA

GW0742
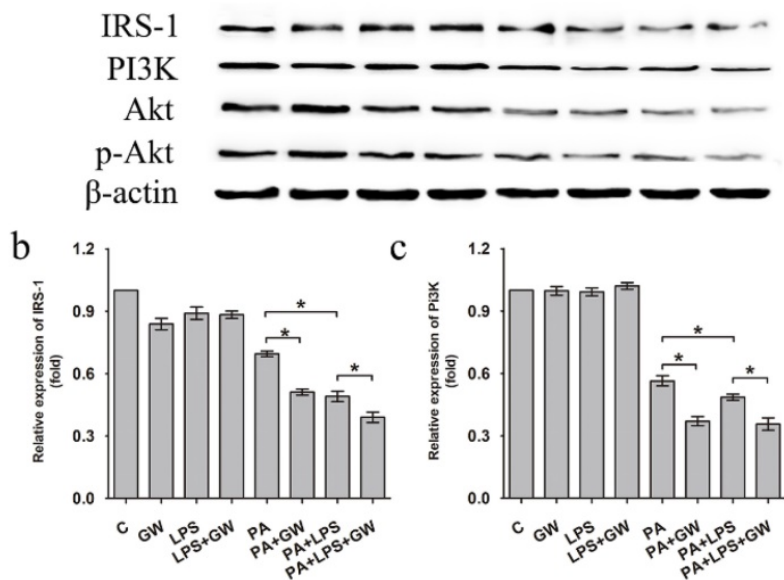

C
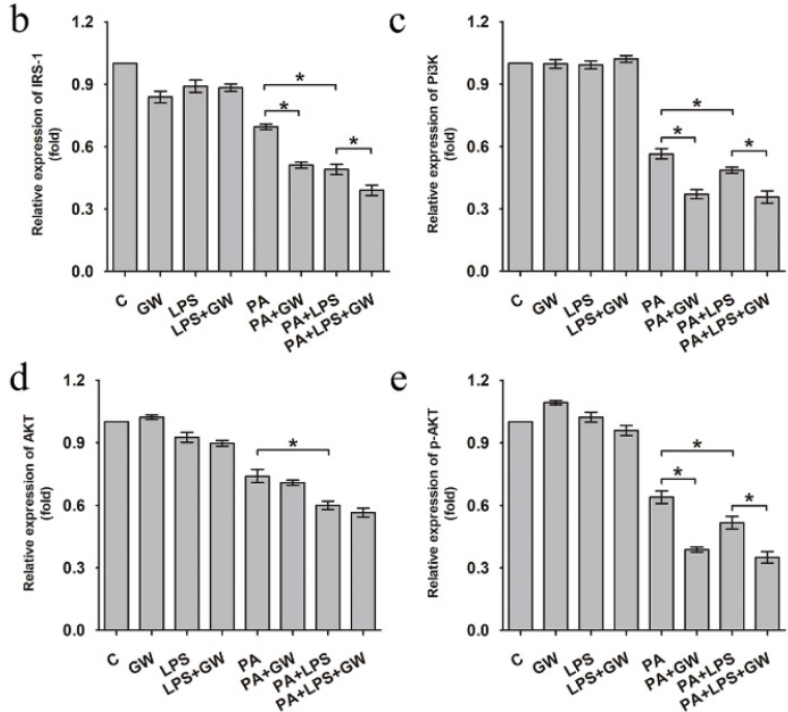

Figure 2. (A) Negative control siRNA (N.C. siRNA) or PPAR $\delta$ siRNA-transfected L02 cells were incubated in 0.4mM palmitic acid or (and) $800 \mathrm{ng} / \mathrm{ml}$ LPS for $24 \mathrm{~h}$. (a) Relative expression level of IRS-1, PI3K, AKT and p-AKT were determined by Western blotting. (b-e) represent relative expression levels of IRS-1, PI3K, AKT and p-AKT. (B) L02 cells were exposed to $0.4 \mathrm{mM}$ palmitic acid or (and) $800 \mathrm{ng} / \mathrm{ml}$ LPS with or without GW0742 treatment. (a) Relative expression level of IRS-1, PI3K, AKT and p-AKT were determined by Western blotting. (b-e) represent relative expression levels of IRS-1, PI3K, AKT and p-AKT. PA, palmitic acid. GW, GW0742.
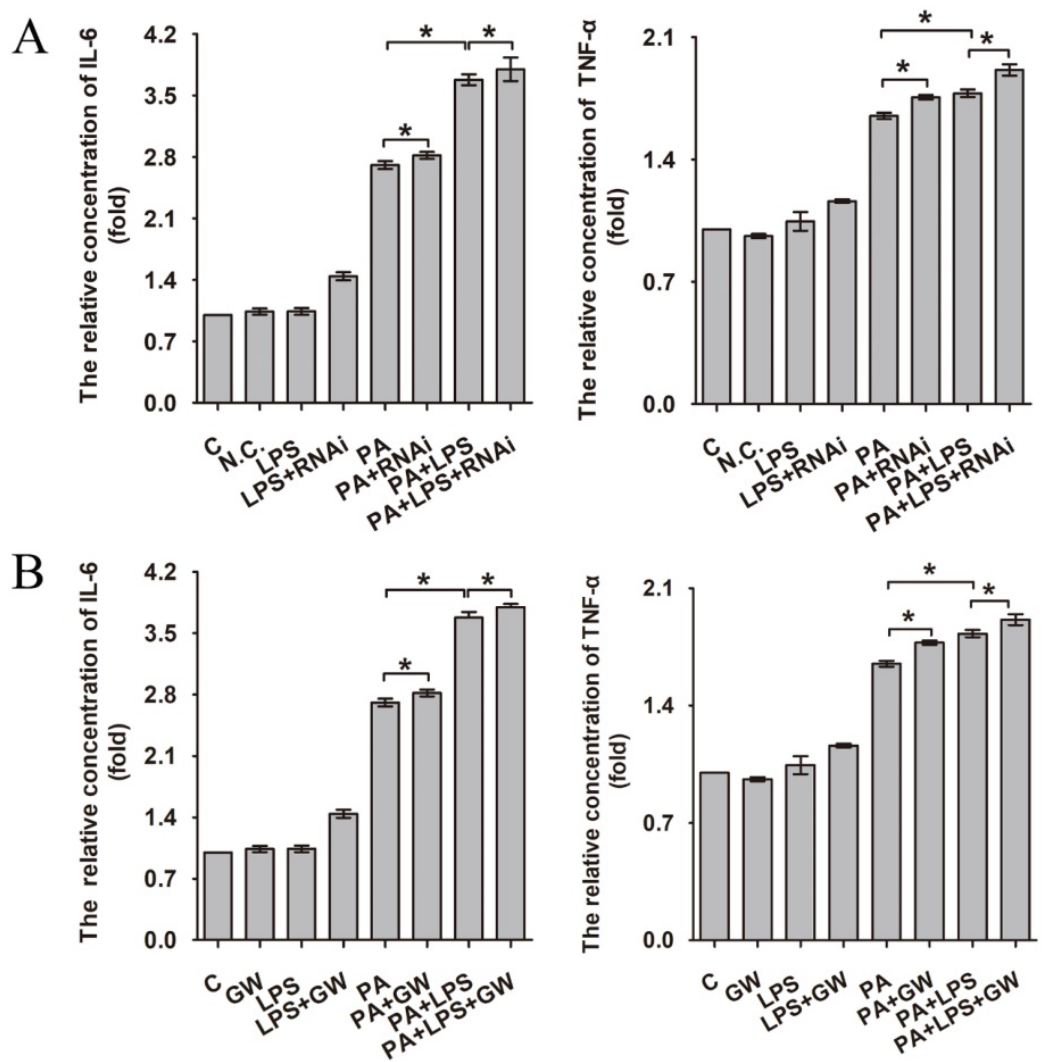

Figure 3. The relative concentration of IL-6 and TNF- $\alpha$. (A) L02 cells were exposed to $0.4 \mathrm{mM}$ palmitic acid or (and) $800 \mathrm{ng} / \mathrm{ml}$ LPS for $24 \mathrm{~h}$ after N.C. siRNA or PPAR $\delta$ siRNA interference. (B) L02 cells were exposed to $0.4 \mathrm{mM}$ palmitic acid or (and) 800ng/ml LPS with or without GW0742 treatment. PA, palmitic acid. GW, GW0742. 
A a LPS

PA

PPAR $\beta / \delta$ RNAi
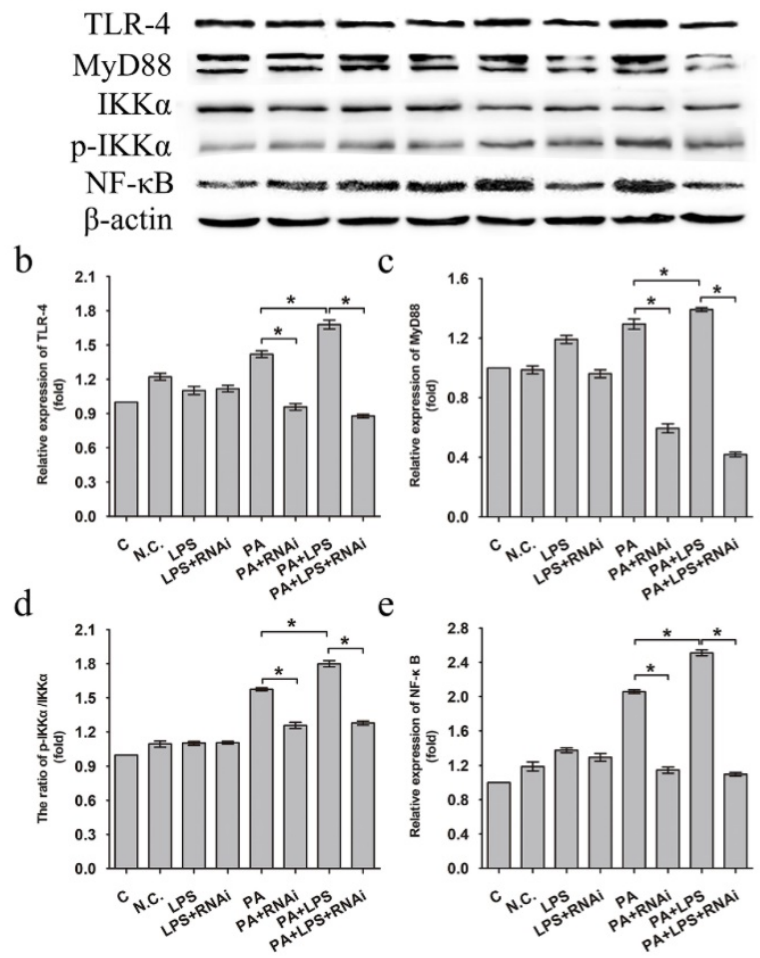

B

a LPS

PA

GW0742

TLR-4

MyD88

IKK $\alpha$

p-IKK $\alpha$

$\mathrm{NF}-\kappa \mathrm{B}$

$\beta$-actin
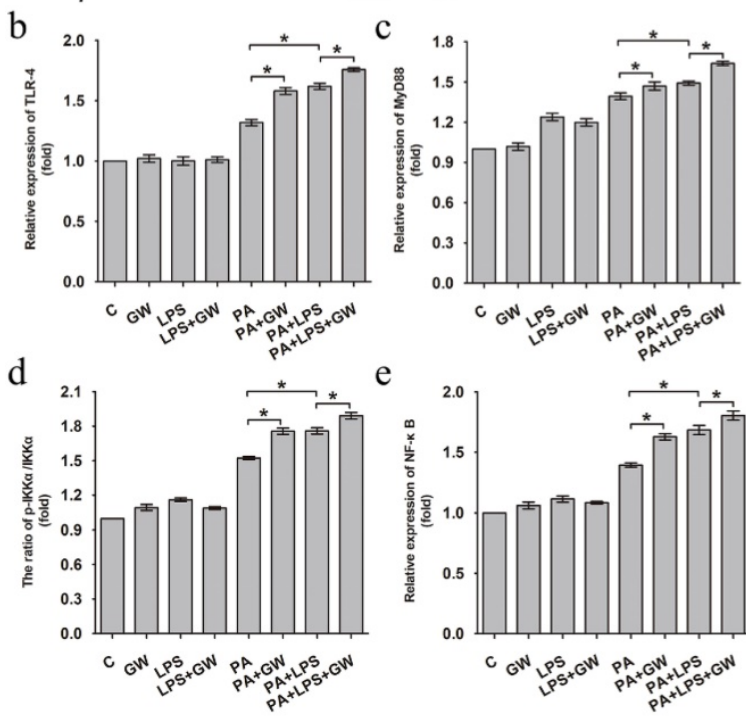

Figure 4. Expression level of TLR-4, MyD88, IKKa, p-IKKa and NF-KB after L02 cells incubated in $0.4 \mathrm{mM}$ palmitic acid or (and) $800 \mathrm{ng} / \mathrm{ml}$ LPS for $24 \mathrm{~h}$ with (A) L02 cells were N.C. siRNA or PPAR $\delta$ siRNA interference, (B) L02 cells were treated with or without GW0742 treatment $(* P<0.05)$. PA, palmitic acid. GW, GW0742.

The expression level of TLR-4, MyD88 and NF-kB was increased in LPS+PA group than PA group (Figure $4 \mathrm{~A} \mathrm{a}, \mathrm{b}, \mathrm{c}, \mathrm{e}$ ). Treatment of si-PPAR $\delta$ caused a marked reduction in the expression levels of TLR-4, MyD88 and NF-KB in both PA and PA+LPS groups (Figure $4 \mathrm{~A} \mathrm{~b}, \mathrm{c}, \mathrm{e}$ ). In contrast, GW0742 caused increased expression levels of TLR-4, MyD88 and NF-kB in PA and PA+LPS groups (Figure $4 \mathrm{~B}$ a, b, c, e). An increased phosphorylation level of IKKa was observed in LPS+PA group in comparison with PA group (Figure $4 \mathrm{~A} \mathrm{~d}$ ). As shown in Figure $4 \mathrm{~A} \mathrm{~d}$ and Figure $4 \mathrm{~B} d$, treatment with si-PPAR $\delta$ reduced the phosphorylation level of IKKa in both PA and PA+LPS groups, whereas the treatment with GW0742 caused a markedly increased expression level of IKKa in both PA and PA+LPS groups.

\section{The effect of PPAR $\delta$ on LPS-mediated apoptosis in NAFLD}

Gut microbiota could lead to an excess accumulation of lipid in the hepatocytes, which result in lipotoxicity and trigger hepatocyte cell death in NAFLD [38]. To elucidate the effects of LPS on apoptosis in FFA treatment L02 cells, Hoechst 33342 staining and Annexin V-FITC/PI double staining were performed. Results of Hoechst 33342 staining showed that the chromatin condensation and number of apoptotic bodies were increased in PA+LPS treated group compared to those of PA group (Figure 5A). Similarly, LPS treatment significantly augmented the percentages of apoptotic cells compared with the PA group (Figure 5B). Hoechst 33342 staining demonstrated that the chromatin condensation and number of apoptotic bodies were decreased in si-PPAR $\delta$ treated groups (Figure 5Aa). PPAR $\delta$ inhibition group' percentage of early and late apoptotic cells is significantly lower than those of the PA group and LPS+PA groups, suggesting that apoptosis of NAFLD was reduced by PPAR $\delta$ inhibition (Figure 5B a, c). By contrast, GW0742 treatment significantly augmented the number of apoptotic bodies and percentages of apoptotic cells compared with the PA and PA+LPS groups (Figure $5 \mathrm{Ab}$ and Figure $5 \mathrm{~B} b, \mathrm{~d})$.

Western blotting analysis showed that related proteins during caspase signal transduction were detected. As shown in Figure 6, the expression levels of Bax, cleaved caspase 3 , and cleaved caspase 8 were elevated after LPS treatment for in PA group. si-PPAR $\delta$ treatment showed obvious reduction in expression levels of Bax, cleaved caspase 3, and cleaved caspase 8 (Figure 6A a, c, d, e). Conversely, the GW0742 treated 

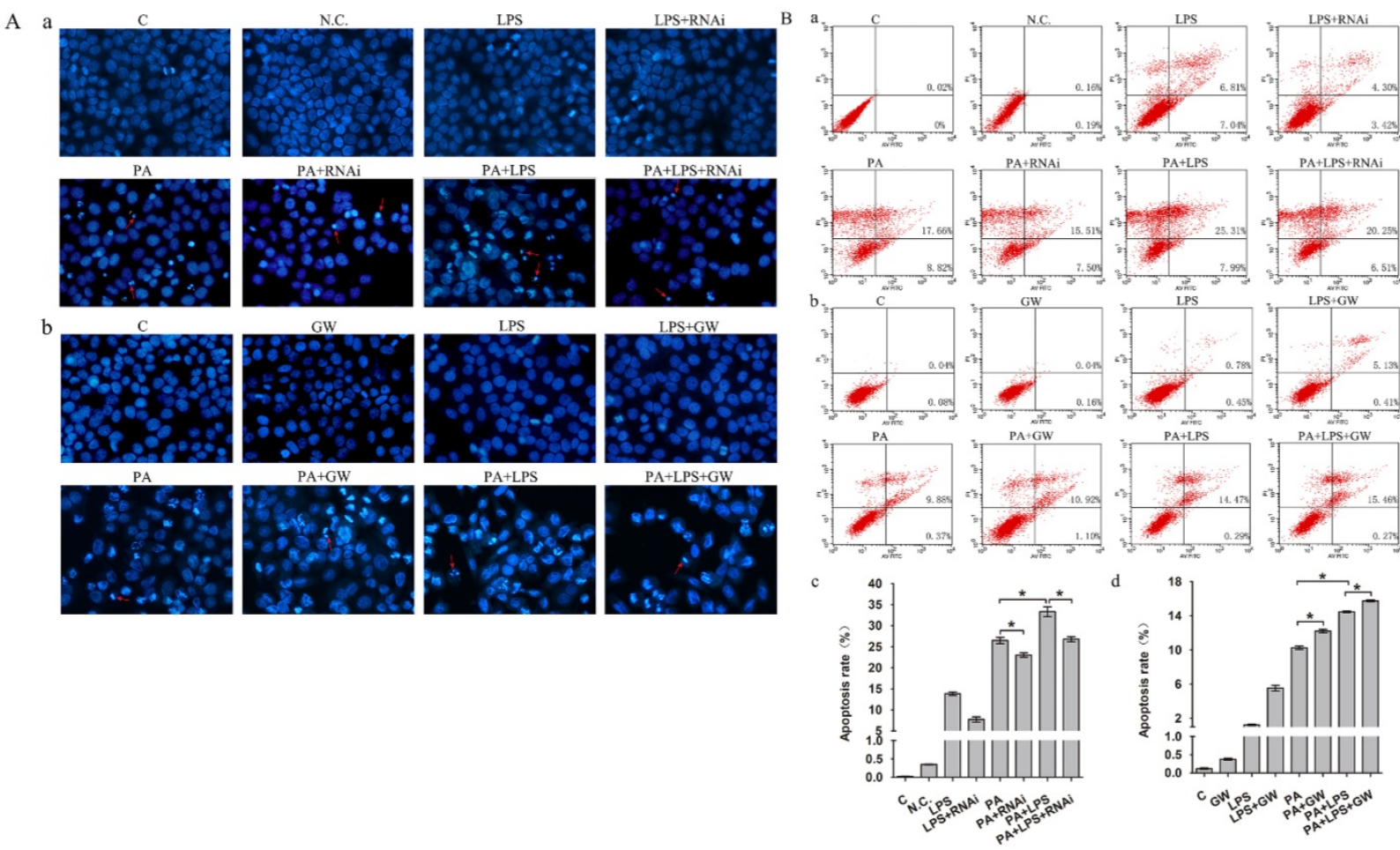

Figure 5. (A) Hoechst 33342 staining results of L02 cells. (a) L02 cells were exposed to $0.4 \mathrm{mM}$ palmitic acid or (and) 800ng/ml LPS for $24 \mathrm{~h}$ after N.C. siRNA or PPAR $\delta$ siRNA interference (magnification, $\times 400$ ). (b) L02 cells were exposed to $0.4 \mathrm{mM}$ palmitic acid or (and) $800 \mathrm{ng} / \mathrm{ml}$ LPS for $24 \mathrm{~h}$ with or without GW0742 treatment (magnification, $\times 400$ ). (B) Detection of apoptotic cells by Annexin V/PI double-staining. (a) L02 cells were treated with N.C. siRNA or PPAR $\delta$ siRNA interference and (b) L02 cells were treated with or without GW0742 treatment. Quantitative analysis of apoptosis. (c) N.C. siRNA or PPAR $\delta$ siRNA interference. (d) L02 cells were treated with or without GW0742 treatment $(* P<0.05)$. PA, palmitic acid. GW, GW0742.

groups upregulated the expression levels of Bax, cleaved caspase 3 and cleaved caspase 8 expression when compared to PA and PA+LPS control groups (Figure 6B a, c, d, e). The expression trend of Bcl-2 was contrary to the above results of Bax, cleaved caspase 3, and cleaved caspase 8 after treatment by LPS, si-PPAR $\delta$, and GW0742 (Figure 6Ab and Figure 6Bb). The result of si-PPAR $\delta$ and GW0742 treatment were completely consistent to the results of cleaved caspase 3 and cleaved caspase 8 expression, suggesting PPAR $\delta$ inhibition reduced apoptosis caused by FFA and LPS in L02 cells.

\section{Discussion}

The mechanism for the development and progression of NAFLD is complex and multifactorial [36, 39-43]. The 'two hits' hypothesis cannot illuminate the pathological mechanism of NAFLD completely. By literature review, we assume that LPS is a pathogenic factor of NAFLD. Nevertheless, there is few studies to assess the role of PPAR $\delta$ in LPS-associated NAFLD. The present study was designed to explore the possible effects of LPS on NAFLD, and to explore the effect of PPAR $\delta$ in this process.

NAFLD is the accumulation of fat in the hepatocytes, in the form of lipid droplets containing triglycerides (TG). Increased delivery of FFA, intrahepatic de novo lipogenesis, and dietary fat are the major mechanisms underlying TG accumulation [44]. In the present study, oil red staining indicated that LPS enhanced the accumulation of TG in L02 cells, comparing with PA treatment (NAFLD model). And the FFA assay results were consistent with those of oil red staining. PPAR $\delta$ inhibition visibly reduced the LPS-induced TG accumulation and downregulated the content of FFA compared with PA treated and PA+LPS treated groups, whereas PPAR $\delta$ activation showed the reverse trend. These results suggest that LPS promotes lipid deposition in hepatocytes and PPAR $\delta$ inhibition may be a protective strategy against LPS-associated lipid accumulation.

Increased intracellular lipid accumulation and levels of serum FFA are due to a failure of insulin-mediated suppression of lipolysis, and being important mediators of insulin resistance [45-47]. Several studies showed that elevated serum levels of LPS may induce hepatocyte steatosis by increasing insulin resistance [27-30]. IRS-1 is the major insulin receptor effector that responsible for the transduction of insulin signaling [48]. And, multiple evidences have suggested that deregulation of the PI3K/AKT signaling pathway is a vital molecular mechanism 
A a LPS

PA

PPAR $\beta / \delta$ RNAi

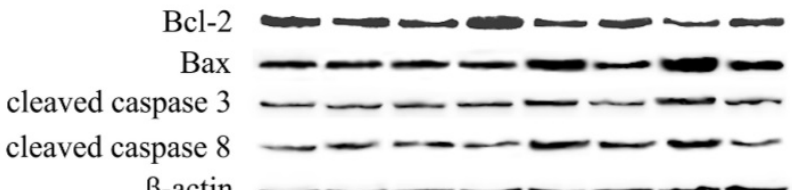

$\beta$-actin
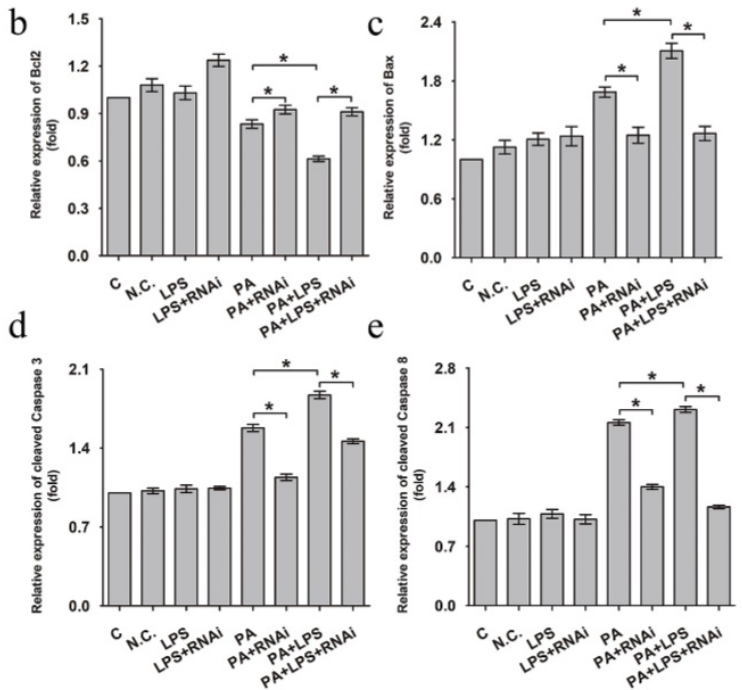
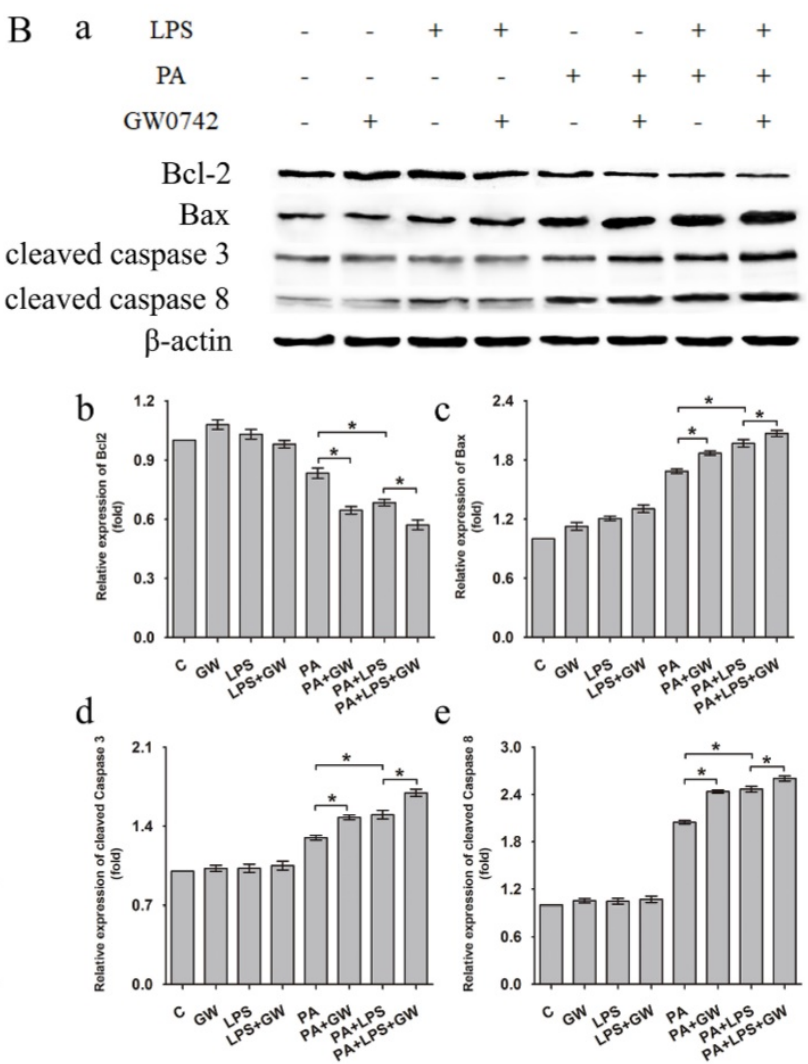

Figure 6. Expression level of Bcl-2, Bax, cleaved Caspase 3, and cleaved Caspase 8 after were exposed to $0.4 \mathrm{mM}$ palmitic acid with or without $800 \mathrm{ng} / \mathrm{ml}$ LPS for $24 \mathrm{~h}$ (A) L02 cells were treated with N.C. siRNA or PPAR $\delta$ siRNA interference or (B) L02 cells were treated with or without GW0742 treatment. PA, palmitic acid. GW, GW0742. PA, palmitic acid. GW, GW0742.

underlying the insulin resistance [49, 50]. Data obtained from western blotting showed that LPS decreased the relative expression levels of IRS-1, PI3K, AKT and phosphorylation of AKT, contributing to insulin resistance. Simultaneously, PPAR $\delta$ inhibition improved LPS-induced depression of the expression of IRS-1, PI3K, AKT and phosphorylation of AKT. Instead, PPAR $\delta$ agonist showed the reverse pattern. The evidence above indicated that LPS may affect insulin resistance through IRS-1/PI3K/AKT pathway, thereby regulating the hepatic lipid accumulation. Meanwhile, PPAR $\delta$ inhibition improves LPS-induced lipid deposition and insulin resistance through regulating IRS-1/PI3K/AKT pathway. Furthermore, PPAR $\delta$ might improve insulin resistance via reducing the delivery of free fatty acids to the liver, promote FFA $\beta$-oxidation, and diminish de novo lipogenesis [51].

Intestinal dysbiosis causes increased intestinal permeability and gut-liver axis dysfunction, leading to increased risk of endotoxemia, followed by the activation of proinflammatory pathways after binding with specific hepatic receptors [52]. Hence, downregulating inflammation level of liver may relieve insulin resistance in NAFLD [53, 54]. Our results showed that LPS upregulated the expression level of two important pro-inflammatory cytokines, IL-6 and TNF-a, through interacting with its principal ligand TLR-4, initiating a TLR4/MyD88/NF-kB signalling cascade culminating in a pro-inflammatory response. Our results are consistent with previous findings [55-59]. In addition, FFA could also activate the pro-inflammatory pathways through membrane receptors. Our result revealed that PPAR $\delta$ inhibition reduced the LPS-induced cytokine expression, such as IL-6 and TNF-a, and secretion by preventing activation of phosphorylation of IKKa and NF- $\mathrm{KB}$, which reduces the inflammation. Moreover, PPAR $\delta$ inhibition probably induces FFA $\beta$-oxidation, reducing their availability for the synthesis of deleterious complex lipids involved in inflammation. Consistent with previous studies, our findings reveal that PPAR $\delta$ could regulate expression of inflammation factors [60, 61].

Recent studies showed that the increased levels of LPS and proinflammatory cytokines led to liver histological changes, such as hepatocyte necrosis and apoptosis [62-64]. In this study, both Annexin V-FITC/PI double staining and Hoechst 33342 staining showed that LPS induced apoptosis in the PA treated group. In addition, LPS and PA treatment upregulated expression levels of apoptotic proteins, 
such as Bax, cleaved caspase 3, and cleaved caspase 8, and downregulated the expression level of Bcl-2 compared with the PA groups. These findings suggest that LPS induce cell apoptosis in NAFLD L02 cell through a mitochondrial apoptotic pathway and caspase-dependent pathway. These results may be due to the enhanced level of FFA and TNF-a [65-67]. Excessive increase of FFAs may result in an increase of mitochondrial damage, resulting in cascade reaction of caspase to induce cell apoptosis [68, 69]. Furthermore, TNF- $\alpha$ might activate caspase 8 relevant apoptotic pathway through the activation of death receptor (Figure 7). Meanwhile, PPAR $\delta$ inhibition alleviated LPS-induced cell apoptosis with depressed protein expression level of cleaved caspase 3, cleaved caspase 8 and Bax in L02 cells. On the contrary, PPAR $\delta$ activation showed the reverse trend. The results indicate that PPAR $\delta$ plays an important role in LPS-induced apoptosis of NAFLD L02 cell. PPAR $\delta$ inhibition probably prevents mitochondria releasing apoptotic factors by upregulating the expression of PI3K/AKT and reduces lipidtoxicity caused by increased FFA.

PPAR $\delta$ play a crucial role in LPS mediated insulin resistance, inflammation and apoptosis in NAFLD L02 cell line. Several studies showed that the PPAR $\delta$ activation modulated multiple parallel paths to decrease the hepatic inflammation, lipotoxicity, insulin resistance and, therefore, mitigate the LPS induced progress of lipid deposition in HepG2 cells and mouse primary liver cells [70, 71]. In contrast, other data indicate that the PPAR $\delta$ activation did not act as protective effects as described. In line with our results, adenovirus-mediated hepatic PPAR $\delta$ over-expression has been shown to activate de novo lipogenesis and subsequent lipid deposition [72]. GW501516 treated $d b / d b$ mice exhibited higher expression of the lipogenic enzyme acetyl-CoA carboxylase- $\beta$ and elevated TG levels in the liver [73]. In PPAR -/- mice, there are no changes in cholesterol, TG, high density lipoprotein cholesterol and FFA with a normal chow diet and there is no data for lipoprotein profiles during feeding by high-fat diets [74]. Therefore, the role of PPAR $\delta$ is still controversial in the repair process of NAFLD. There are several possible reasons explainning the observed differences. One crucial factor is due to dissimilarities in PPAR $\delta$ tissue expression patterns among human, mouse and rat [75-77]. Besides, PPAR $\delta$ is widely expressed in many organs $[31,78]$, So, PPAR $\delta$ activation might increase fatty acid oxidative capacity and energy dissipation in skeletal muscle cells, thus improving hepatic steatosis. Last but not the least, short-term treatment with PPAR $\delta$ agonists reportedly yields a transient increase in hepatic TG levels [78].

To summarize, LPS may be a key factor in development of NAFLD, and PPAR $\delta$ inhibition protects the liver in case of the NAFLD progression, which provides a new evidence of PPAR $\delta$ in the molecular pathogenesis of LPS-related NAFLD damage. Due to limited time and energy, in vivo experiment is not executed. We are conducting experiments in vivo to compensate for the insufficient evidence, in vitro. All authors read and approved the final manuscript.

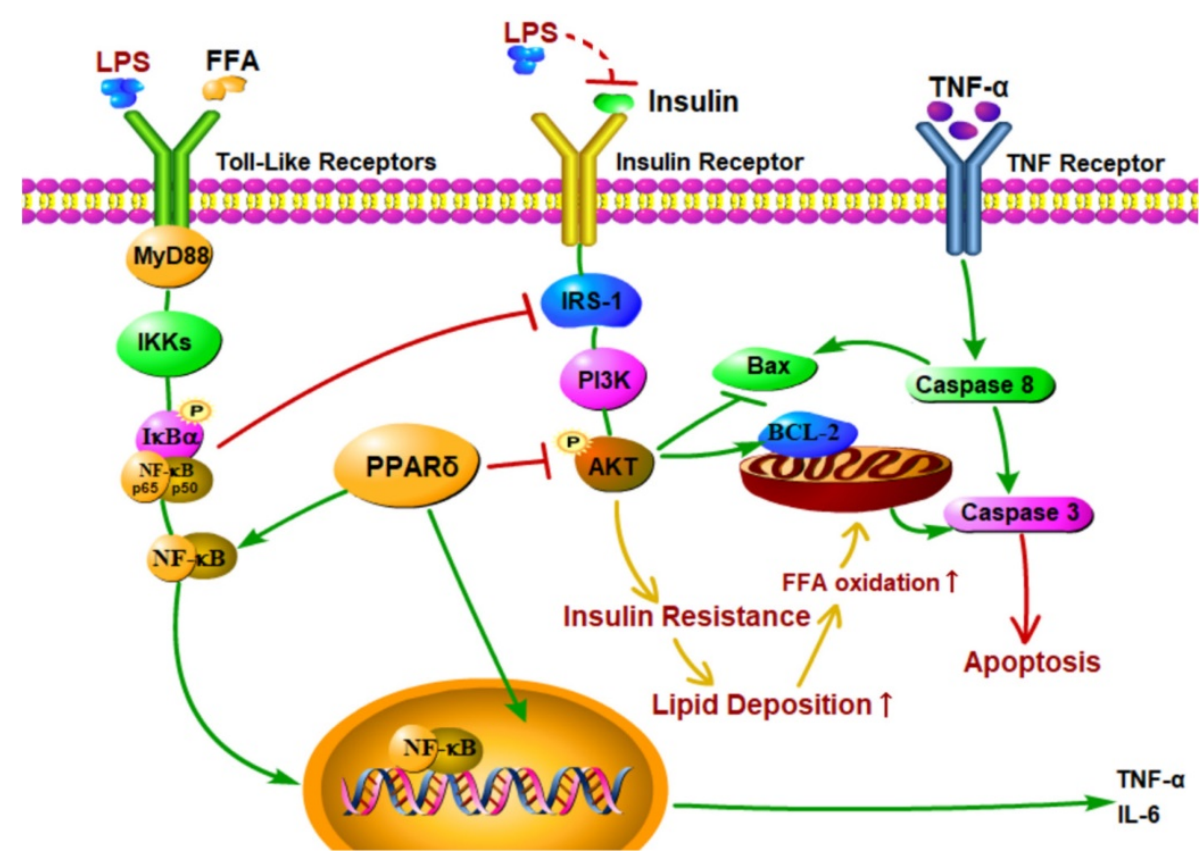

Figure 7. Proposed mechanisms for PPAR $\delta$ inhibition protects against palmitic acid-LPS induced lipidosis and injury in L02 cell by adjusting lipid accumulation, insulin resistance, pro-inflammation and apoptosis-associated proteins. 


\section{Abbreviations}

NAFLD: Non-alcoholic fatty liver disease; NASH: non-alcoholic steatohepatitis; HCC: hepatocellular carcinoma; IR: insulin resistance; LPS: lipopolysaccharides; TLR-4: Toll-like receptor 4; PPAR ס: Peroxisome proliferator-activated receptor $\delta$; FFA: free fatty acid; HDL: high-density lipoprotein.

\section{Acknowledgements}

This research was funded by the National Natural Science Foundation of China, No.81360141 and No. 81770525 . And this study was also funded by grant from the Youth Fund Projects of Science and Technology from Gansu Province (No. 17JR5RA233) and Natural Science Foundation Youth Project of Gansu Province (No. 18JR3RA332).

\section{Authors' Contributions}

Conceived and designed the experiments: BL, YY. Performed the experiments: CW, JL, YH, JC, YL. Analyzed the data: $\mathrm{CW}, \mathrm{JL}, \mathrm{KH}$. Wrote the paper: $\mathrm{CW}$, YL.

\section{Competing Interests}

The authors have declared that no competing interest exists.

\section{References}

1. Angulo P. Nonalcoholic fatty liver disease. $N$ Engl J Med. 2002;346(16):1221-31

2. Pais R, Charlotte F, Fedchuk L, et al. A systematic review of follow-up biopsies reveals disease progression in patients with non-alcoholic fatty liver. J Hepatol. 2013;59(3):550-6

3. Singh S, Allen AM, Wang Z, et al. Fibrosis progression in nonalcoholic fatty liver vs nonalcoholic steatohepatitis: a systematic review and meta-analysis of paired-biopsy studies. Clin Gastroenterol Hepatol. 2015;13(4):643-54 e1-9; quiz e39-40.

4. Torres DM, Williams CD, Harrison SA. Features, diagnosis, and treatment of nonalcoholic fatty liver disease. Clin Gastroenterol Hepatol. 2012;10(8):837-58.

5. Satapathy SK, Sanyal AJ. Novel treatment modalities for nonalcoholic steatohepatitis. Trends Endocrinol Metab. 2010;21(11):668-75.

6. Charlton M. Evolving aspects of liver transplantation for nonalcoholic steatohepatitis. Curr Opin Organ Transplant. 2013;18(3):251-8.

7. He L, Liu X, Wang L, et al. Thiazolidinediones for nonalcoholic steatohepatitis: A meta-analysis of randomized clinical trials. Medicine (Baltimore). 2016;95(42):e4947.

8. Yoneda M, Hasegawa T, Sato K. Vitamin E therapy for NAFLD/NASH. Nutrition. 2015;31(6):898-9.

9. Rosso N, Marin V, Giordani A, et al. The Pros and the Cons for the Use of Silybin-Rich Oral Formulations in Treatment of Liver Damage (NAFLD in Particular). Curr Med Chem. 2015;22(25):2954-71.

10. Buzzetti E, Pinzani M, Tsochatzis EA. The multiple-hit pathogenesis of non-alcoholic fatty liver disease (NAFLD). Metabolism. 2016;65(8):1038-48

11. Cusi K. Role of obesity and lipotoxicity in the development of nonalcoholic steatohepatitis: pathophysiology and clinical implications. Gastroenterology. 2012;142(4):711-25 e6.

12. Koppe SW. Obesity and the liver: nonalcoholic fatty liver disease. Transl Res. 2014;164(4):312-22.

13. Peyre L, Rouimi P, de Sousa G, et al. Comparative study of bisphenol A and its analogue bisphenol $S$ on human hepatic cells: a focus on their potential involvement in nonalcoholic fatty liver disease. Food Chem Toxicol. 2014;70:9-18.

14. Chen H, Zhang W, Rui BB, et al. Di(2-ethylhexyl) phthalate exacerbates non-alcoholic fatty liver in rats and its potential mechanisms. Environ Toxicol Pharmacol. 2016;42:38-44.

15. Miele L, Marrone G, Lauritano C, et al. Gut-liver axis and microbiota in NAFLD: insight pathophysiology for novel therapeutic target. Curr Pharm Des. 2013;19(29):5314-24.
16. Tremaroli V, Backhed F. Functional interactions between the gut microbiota and host metabolism. Nature. 2012;489(7415):242-9.

17. Lau E, Carvalho D, Freitas P. Gut Microbiota: Association with NAFLD and Metabolic Disturbances. Biomed Res Int. 2015;2015:979515.

18. Ma J, Zhou Q, Li H. Gut Microbiota and Nonalcoholic Fatty Liver Disease: Insights on Mechanisms and Therapy. Nutrients. 2017;9(10).

19. Sanz Y, Santacruz A, Gauffin P. Gut microbiota in obesity and metabolic disorders. Proc Nutr Soc. 2010;69(3):434-41.

20. Everard A, Cani PD. Diabetes, obesity and gut microbiota. Best Pract Res Clin Gastroenterol. 2013;27(1):73-83.

21. Delzenne NM, Knudsen $C$, Beaumont $M$, et al. Contribution of the gut microbiota to the regulation of host metabolism and energy balance: a focus on the gut-liver axis. Proc Nutr Soc. 2019:1-10.

22. Compare D, Coccoli P, Rocco A, et al. Gut--liver axis: the impact of gut microbiota on non alcoholic fatty liver disease. Nutr Metab Cardiovasc Dis. 2012;22(6):471-6.

23. Nagata K, Suzuki H, Sakaguchi S. Common pathogenic mechanism in development progression of liver injury caused by non-alcoholic or alcoholic steatohepatitis. J Toxicol Sci. 2007;32(5):453-68

24. Larsson E, Tremaroli V, Lee YS, et al. Analysis of gut microbial regulation of host gene expression along the length of the gut and regulation of gut microbial ecology through MyD88. Gut. 2012;61(8):1124-31.

25. Lu YC, Yeh WC, Ohashi PS. LPS/TLR4 signal transduction pathway. Cytokine. 2008;42(2):145-51

26. Cani PD, Amar J, Iglesias MA, et al. Metabolic endotoxemia initiates obesity and insulin resistance. Diabetes. 2007;56(7):1761-72.

27. Mehta NN, McGillicuddy FC, Anderson PD, et al. Experimental endotoxemia induces adipose inflammation and insulin resistance in humans. Diabetes. 2010;59(1):172-81.

28. Holland WL, Bikman BT, Wang LP, et al. Lipid-induced insulin resistance mediated by the proinflammatory receptor TLR4 requires saturated fatty acid-induced ceramide biosynthesis in mice. J Clin Invest. 2011;121(5):1858-70.

29. Tilg H, Moschen AR. Inflammatory mechanisms in the regulation of insulin resistance. Mol Med. 2008;14(3-4):222-31.

30. Tailleux A, Wouters $K$, Staels B. Roles of PPARs in NAFLD: potential therapeutic targets. Biochim Biophys Acta. 2012;1821(5):809-18.

31. Gross BS, Fruchart J-C, Staels B. Peroxisome Proliferator-Activated Receptor $\beta / \delta$ : A novel target for the reduction of atherosclerosis. Drug Discovery Today: Therapeutic Strategies. 2005;2(3): 237-43.

32. Qin X, Xie X, Fan Y, et al. Peroxisome proliferator-activated receptor-delta induces insulin-induced gene-1 and suppresses hepatic lipogenesis in obese diabetic mice. Hepatology. 2008;48(2):432-41.

33. Wu HT, Chen CT, Cheng KC, et al. Pharmacological activation of peroxisome proliferator-activated receptor delta improves insulin resistance and hepatic teatosis in high fat diet-induced diabetic mice. Horm Metab Res. 2011;43(9):631-5

34. Bojic LA, Telford DE, Fullerton MD, et al. PPARdelta activation attenuates hepatic steatosis in Ldlr-/- mice by enhanced fat oxidation, reduced lipogenesis, and improved insulin sensitivity. J Lipid Res. 2014;55(7):1254-66.

35. Barroso E, Rodriguez-Calvo R, Serrano-Marco L, et al. The PPARbeta/delta activator GW501516 prevents the down-regulation of AMPK caused by a high-fat diet in liver and amplifies the PGC-1alpha-Lipin 1-PPARalpha pathway leading to increased fatty acid oxidation. Endocrinology. 2011;152(5):1848-59.

36. Donnelly KL, Smith CI, Schwarzenberg SJ, et al. Sources of fatty acids stored in liver and secreted via lipoproteins in patients with nonalcoholic fatty liver disease. J Clin Invest. 2005;115(5):1343-51.

37. Povero D, Feldstein AE. Novel Molecular Mechanisms in the Development of Non-Alcoholic Steatohepatitis. Diabetes Metab J. 2016:40(1):1-11.

38. Yeh MM, Brunt EM. Pathology of nonalcoholic fatty liver disease. Am J Clin Pathol. 2007;128(5):837-47.

39. Vanni E, Bugianesi $\mathrm{E}$, Kotronen $\mathrm{A}$, et al. From the metabolic syndrome to NAFLD or vice versa? Dig Liver Dis. 2010;42(5):320-30

40. Peverill W, Powell LW, Skoien R. Evolving concepts in the pathogenesis of NASH: beyond steatosis and inflammation. Int J Mol Sci. 2014;15(5):8591-638.

41. Marra F, Gastaldelli A, Svegliati Baroni G, et al. Molecular basis and mechanisms of progression of non-alcoholic steatohepatitis. Trends Mol Med. 2008;14(2):72-81.

42. Nobili V, Svegliati-Baroni G, Alisi A, et al A 360-degree overview of paediatric NAFLD: recent insights. J Hepatol. 2013;58(6):1218-29.

43. De SM, Day C, Svegliati-Baroni G. From NAFLD to NASH and HCC: pathogenetic mechanisms and therapeutic insights. Curr Pharm Des. 2013;19(29):5239-49.

44. Tilg H, Hotamisligil GS. Nonalcoholic fatty liver disease: Cytokine-adipokine interplay and regulation of insulin resistance. Gastroenterology. 2006:131(3):934-45.

45. Utzschneider KM, Kahn SE. Review: The role of insulin resistance in nonalcoholic fatty liver disease. J Clin Endocrinol Metab. 2006;91(12):4753-61.

46. Rector RS, Thyfault JP, Uptergrove GM, et al. Mitochondrial dysfunction precedes insulin resistance and hepatic steatosis and contributes to the natural history of non-alcoholic fatty liver disease in an obese rodent model. J Hepatol. 2010;52(5):727-36.

47. Thirone AC, Huang C, Klip A. Tissue-specific roles of IRS proteins in insulin signaling and glucose transport. Trends Endocrinol Metab. 2006;17(2):72-8. 
48. Hwang HJ, Jung TW, Kim BH, et al. A dipeptidyl peptidase-IV inhibitor improves hepatic steatosis and insulin resistance by AMPK-dependent and JNK-dependent inhibition of LECT2 expression. Biochem Pharmacol. 2015;98(1):157-66

49. Zhang Y, Hai J, Cao M, et al. Silibinin ameliorates steatosis and insulin resistance during non-alcoholic fatty liver disease development partly through targeting IRS-1/PI3K/Akt pathway. Int Immunopharmacol. 2013;17(3):714-20.

50. Palomer X, Barroso E, Pizarro-Delgado J, et al. PPAR beta/delta: A Key Therapeutic Target in Metabolic Disorders. Int J Mol Sci. 2018;19(3).

51. Marra F, Svegliati-Baroni G. Lipotoxicity and the gut-liver axis in NASH pathogenesis. J Hepatol. 2018;68(2):280-95.

52. $\mathrm{Li} \mathrm{Z}$, Yang $\mathrm{S}$, Lin $\mathrm{H}$, et al. Probiotics and antibodies to TNF inhibit inflammatory activity and improve nonalcoholic fatty liver disease. Hepatology. 2003;37(2):343-50.

53. Asrih M, Jornayvaz FR. Inflammation as a potential link between nonalcoholic fatty liver disease and insulin resistance. J Endocrinol. 2013;218(3):R25-36.

54. Roh YS, Seki E. Toll-like receptors in alcoholic liver disease, non-alcoholic steatohepatitis and carcinogenesis. J Gastroenterol Hepatol. 2013;28 Suppl 1:38-42.

55. Ceccarelli S, Nobili V, Alisi A. Toll-like receptor-mediated signaling cascade as a regulator of the inflammation network during alcoholic liver disease. World J Gastroenterol. 2014;20(44):16443-51.

56. Paik YH, Schwabe RF, Bataller R, et al. Toll-like receptor 4 mediates inflammatory signaling by bacterial lipopolysaccharide in human hepatic stellate cells. Hepatology. 2003;37(5):1043-55.

57. Brun P, Castagliuolo I, Pinzani M, et al. Exposure to bacterial cell wall products triggers an inflammatory phenotype in hepatic stellate cells. Am J Physiol Gastrointest Liver Physiol. 2005;289(3):G571-8.

58. Eaton HE, Desrochers G, Drory SB, et al. SIMPLE/LITAF expression induces the translocation of the ubiquitin ligase itch towards the lysosomal compartments. PLoS One. 2011;6(2):e16873.

59. Bishop-Bailey D, Bystrom J. Emerging roles of peroxisome proliferator-activated receptor-beta/delta in inflammation. Pharmacol Ther. 2009;124(2):141-50.

60. Chen J, Montagner A, Tan NS, et al. Insights into the Role of PPARbeta/delta in NAFLD. Int J Mol Sci. 2018;19(7).

61. Tomita K, Tamiya G, Ando S, et al. Tumour necrosis factor alpha signalling through activation of Kupffer cells plays an essential role in liver fibrosis of non-alcoholic steatohepatitis in mice. Gut. 2006;55(3):415-24.

62. Poniachik J, Csendes A, Diaz JC, et al. Increased production of IL-1alpha and TNF-alpha in lipopolysaccharide-stimulated blood from obese patients with non-alcoholic fatty liver disease. Cytokine. 2006;33(5):252-7.

63. Stojsavljević $\mathrm{S}$, Palčić M G, Jukić L V, et al. Adipokines and proinflammatory cytokines, the key mediators in the pathogenesis of nonalcoholic fatty liver disease. World J Gastroenterol. 2014;20(48):18070-91.

64. Kudo H, Takahara $\mathrm{T}$, Yata $\mathrm{Y}$, et al. Lipopolysaccharide triggered TNF-alpha-induced hepatocyte apoptosis in a murine non-alcoholic steatohepatitis model. J Hepatol. 2009;51(1):168-75.

65. Zhang W, Kudo H, Kawai K, et al. Tumor necrosis factor-alpha accelerates apoptosis of steatotic hepatocytes from a murine model of non-alcoholic fatty liver disease. Biochem Biophys Res Commun. 2010;391(4):1731-6.

66. Feldstein AE, Gores GJ. Apoptosis in alcoholic and nonalcoholic steatohepatitis. Front Biosci. 2005;10:3093-9.

67. Ibrahim SH, Kohli R, Gores GJ. Mechanisms of lipotoxicity in NAFLD and clinical implications. J Pediatr Gastroenterol Nutr. 2011:53(2):131-40.

68. Gambino R, Bugianesi E, Rosso C, et al. Different Serum Free Fatty Acid Profiles in NAFLD Subjects and Healthy Controls after Oral Fat Load. Int J Mol Sci. 2016;17(4):479.

69. Lee HJ, Yeon JE, Ko EJ, et al. Peroxisome proliferator-activated receptor-delta agonist ameliorated inflammasome activation in nonalcoholic fatty liver disease. World J Gastroenterol. 2015;21(45):12787-99.

70. Shan $\mathrm{W}$, Nicol CJ, Ito $\mathrm{S}$, et al. Peroxisome proliferator-activated receptor-beta/delta protects against chemically induced liver toxicity in mice. Hepatology. 2008;47(1):225-35.

71. Liu S, Hatano B, Zhao M, et al. Role of peroxisome proliferator-activated receptor $\{$ delta\}/\{beta\} in hepatic metabolic regulation. J Biol Chem. 2011;286(2):1237-47.

72. Lee $\mathrm{CH}$, Olson $\mathrm{P}$, Hevener A, et al. PPARdelta regulates glucose metabolism and insulin sensitivity. Proc Natl Acad Sci U S A. 2006;103(9):3444-9.

73. Barak Y, Liao D, He W, et al. Effects of peroxisome proliferator-activated receptor delta on placentation, adiposity, and colorectal cancer. Proc Natl Acad Sci U S A. 2002;99(1):303-8.

74. Kliewer SA, Forman BM, Blumberg B, et al. Differential expression and activation of a family of murine peroxisome proliferator-activated receptors. Proc Natl Acad Sci U S A. 1994;91(15):7355-9.

75. Braissant $\mathrm{O}$, Foufelle F, Scotto $\mathrm{C}$, et al. Differential expression of peroxisome proliferator-activated receptors (PPARs): tissue distribution of PPAR-alpha, -beta, and -gamma in the adult rat. Endocrinology. 1996;137(1):354-66.

76. Girroir EE, Hollingshead $\mathrm{HE}, \mathrm{He} \mathrm{P}$, et al. Quantitative expression patterns of peroxisome proliferator-activated receptor-beta/delta (PPARbeta/delta) protein in mice. Biochem Biophys Res Commun. 2008;371(3):456-61.

77. Abbott BD. Review of the expression of peroxisome proliferator-activated receptors alpha (PPAR alpha), beta (PPAR beta), and gamma (PPAR gamma) in rodent and human development. Reprod Toxicol. 2009;27(3-4):246-57.
78. Garbacz WG, Huang JT, Higgins LG, et al. PPARalpha Is Required for PPARdelta Action in Regulation of Body Weight and Hepatic Steatosis in Mice. PPAR Res. 2015;2015:927057. 